\title{
STOMACH
}

\section{Risk factors for peptic ulcer disease: a population based prospective cohort study comprising 2416 Danish adults}

\author{
S Rosenstock, T Jørgensen, O Bonnevie, L Andersen
}

Gut 2003;52:186-193

See end of article for authors' affiliations

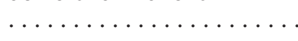

Correspondence to: Dr S Rosenstock,

Department of Surgery D26, Glostrup University Hospital, Nordre Ringvej 2600 Glostrup, Denmark rosenstock.s@dadlnet.dk

Accepted for publication 3 September 2002

\begin{abstract}
Background: No population based prospective cohort study has previously assessed the impact of multiple risk factors, including Helicobacter pylori infection, on the incidence of peptic ulcer disease (PUD).

Aims: To identify risk factors for PUD and estimate their relative impact on ulcer incidence.

Subjects: Random sample of 2416 Danish adults with no history of PU.

Methods: Sample members were interviewed in 1982 and 1994. PUs diagnosed within the observation period were verified through medical records. Information on psychosocial factors, lifestyle practices, and medication was obtained from a questionnaire completed at study entry. $H$ pylori infection status was determined by ELISA.

Results: The main risk factors for PUD were $H$ pylori infection lodds ratio $4.3195 \%$ confidence interval $2.2 ; 8.3))$, tobacco smoking $(3.8(1.7 ; 9.8))$, and use of minor tranquillisers $(3.0(1.4 ; 6.6))$. Intake of non-steroid anti-inflammatory drugs did not affect the incidence of PUD $(0.4(0.1 ; 2.3))$. In those with increased antibodies to $H$ pylori, tobacco smoking $(12.7(2.8 ; 56.8))$ and intake of spirits $(2.4(1.1$; $5.4))$ increased the risk of PUD whereas moderate leisure time physical activity $(0.3(0.2 ; 0.7))$ protected against PUD.

Conclusions: Tobacco smoking and $H$ pylori infection are the main risk factors for PUD in Danish adults. Physical activity may protect against PUD in those infected with $\mathrm{H}$ pylori.
\end{abstract}

A though it is generally accepted that the aetiology of peptic ulcer disease (PUD) is multifactorial, data on the relative impact of single risk factors are scarce. A number of population based prospective studies have been published $^{1-6}$ but so far no study has assessed the effect of Helicobacter pylori infection together with other PUD determinants. A meta-analysis suggested that $95 \%$ of all hospitalised ulcer cases in the USA were attributable to H pylori infection, use of non-steroidal anti-inflammatory drugs (NSAIDs), and tobacco smoking. ${ }^{7}$ Hospitalised ulcer cases differ from uncomplicated ulcer cases in terms of aetiology and comorbidity. Moreover, $H$ pylori infection rates vary considerably between continents. ${ }^{8}$ It is therefore likely that PU risk factors contribute differently to ulcer occurrence in general populations as well as to ulcer occurrence in different parts of the world..$^{10}$

The aims of this study were: firstly, to identify risk factors for PUD and estimate their relative impact on ulcer incidence in Denmark; and secondly, to identify possible interactions between factors that relate to ulcer incidence.

\section{MATERIALS AND METHODS \\ Study population}

A random sample of 4581 Danish adults aged exactly 30, 40, 50, and 60 years were invited to a population study in October 1982. ${ }^{11}$ A total of 3608 subjects (78.8\%) accepted the invitation. By January 1993, 451 members of the original sample had died or disappeared. The remaining 4130 sample members were invited to a follow up examination. A total of 2656 subjects attended the follow up which took place between June 1993 and December 1994. ${ }^{12}$ The Regional Research Ethics Committee of Copenhagen County approved the project.

\section{Collection of sera and diagnosis of $\boldsymbol{H}$ pylori infection}

Large scale testing for antibodies to $H$ pylori became available in the beginning of the 1990s in Denmark. Blood samples had already been drawn from 3590 participants at study entry in
1982. In June 1993, all samples were thawed and analysed for IgG antibodies (anti-Hp IgG) to H pylori. Blood samples drawn at follow up $(\mathrm{n}=2541)$ were examined continuously. Matching pairs of sera were identified in 2527 cases. A total of 2416 of these participants had no history of PUD when entering the study and were eligible for the present study.

IgG antibodies directed against a low molecular weight fraction of $H$ pylori antigens were measured with a validated inhouse indirect ELISA. ${ }^{13-15}$ IgG antibody levels were categorised as seronegative, borderline increased, or seropositive. Sensitivity, specificity, positive predictive value, and negative predictive value of the IgG serology assay were $98.5 \%, 54.0 \%$, $76.1 \%$, and $96.2 \%$, respectively

\section{Peptic ulcer diagnosis}

All participants were asked if they had been diagnosed with a peptic ulcer within the 11 year observation period. Participants with a first time diagnosed ulcer reported how and when the diagnosis was made. To ensure that all first time diagnosed ulcers were recorded, information was also obtained from the National Danish Hospital Discharge Registry (NDHDR) in which all cases of hospital admissions in Denmark are registered with a discharge diagnosis. The search included the following PUD diagnoses (WHO ICD-8 codes: 531.X (gastric ulcer), 532.X (duodenal ulcer), and 533.X (gastro-duodenal ulcer)). Medical records from those who reported an ulcer or who were registered with a PUD diagnosis in the NDHDR were retrieved and reviewed. Only ulcers verified by upper endoscopy, barium meal examination, or surgery were regarded as true incident ulcers. Active ulcers were considered to be gastric ulcers (GUs) when a crater with appreciable depth was seen in

Abbreviations: PUD, peptic ulcer disease; NSAIDs, non-steroidal anti-inflammatory drugs; GU, gastric ulcer; DU, duodenal ulcer; PPI proton pump inhibitor. 
Table 1 Eleven year cumulated incidence of peptic ulcer disease (PUD) in 1994 by categories of baseline exposures: Helicobacter pylori infection and lifestyle practices. Unadjusted and sex and age adjusted odds ratios (OR, 95\% confidence intervals (CI))

\begin{tabular}{|c|c|c|c|c|c|c|}
\hline \multirow{2}{*}{$\begin{array}{l}\text { Baseline exposure } \\
\text { (reference category) }\end{array}$} & \multicolumn{2}{|c|}{ PUD incidence } & \multicolumn{2}{|l|}{ Unadjusted } & \multicolumn{2}{|c|}{ Sex and age adjusted } \\
\hline & $\%$ & $\mathrm{n}$ & Odds ratio & $95 \% \mathrm{Cl}$ & Odds ratio & $95 \% \mathrm{Cl}$ \\
\hline \multicolumn{7}{|l|}{ Anti-Hp lg $G$ sero-status } \\
\hline (Seronegative) & 1.3 & 1412 & 1.0 & - & 1.0 & - \\
\hline Borderline & 5.7 & 456 & 4.7 & $2.5 ; 8.6$ & 4.5 & $2.4 ; 8.3$ \\
\hline Seropositive & 4.7 & 548 & 3.9 & $3.9 ; 7.1$ & 3.6 & $1.9 ; 6.7$ \\
\hline \multicolumn{7}{|c|}{ Anti-Hp changes within the observation period } \\
\hline (Persistently seronegative) & 1.1 & 1286 & 1.0 & - & 1.0 & - \\
\hline Persistently borderline & 3.0 & 305 & 2.8 & $1.2 ; 6.4$ & 2.7 & $1.1 ; 6.3$ \\
\hline Persistently seropositive & 4.1 & 459 & 3.9 & $2.0 ; 7.9$ & 3.7 & $1.8 ; 7.6$ \\
\hline Changes in anti-Hp infection status & 5.0 & 343 & 4.7 & $2.3 ; 9.7$ & 4.6 & $2.2 ; 9.5$ \\
\hline \multicolumn{7}{|c|}{ Cumulative tobacco consumption } \\
\hline (Never smoker) & 1.0 & 691 & 1.0 & - & 1.0 & - \\
\hline Former smoker & 2.1 & 482 & 2.1 & $0.8 ; 5.5$ & 2.1 & $0.8 ; 5.6$ \\
\hline $1-14.99 \mathrm{~g} /$ day & 4.0 & 596 & 4.1 & $1.8 ; 9.6$ & 4.4 & $1.9 ; 10.3$ \\
\hline $15-24.99 \mathrm{~g} /$ day & 4.3 & 535 & 4.4 & $1.8 ; 10.2$ & 5.1 & $2.1 ; 12.0$ \\
\hline$\geqslant 25 \mathrm{~g} /$ day & 4.8 & 126 & 4.9 & $1.6 ; 14.8$ & 5.9 & $1.8 ; 18.0$ \\
\hline \multicolumn{7}{|c|}{ Cumulative number of cigarettes smoked daily* } \\
\hline (0) & 1.9 & 996 & 1.0 & - & 1.0 & - \\
\hline $1-9$ cigarettes & 2.7 & 374 & 1.4 & $0.7 ; 3.1$ & 1.5 & $0.7 ; 3.2$ \\
\hline $10-14$ cigarettes & 2.7 & 369 & 1.4 & $0.7 ; 3.1$ & 1.6 & $0.7 ; 3.5$ \\
\hline $15-20$ cigarettes & 5.0 & 556 & 2.1 & $1.1 ; 3.9$ & 2.4 & $1.3 ; 4.5$ \\
\hline$\geqslant 21$ cigarettes & 6.7 & 135 & 3.7 & $1.6 ; 8.3$ & 4.3 & $1.9 ; 9.9$ \\
\hline \multicolumn{7}{|l|}{ Wine (weekly consumption) } \\
\hline (Never drink wine) & 4.2 & 690 & 1.0 & - & 1.0 & - \\
\hline $1-3$ glasses of wine & 2.2 & 1112 & 0.5 & $0.3 ; 0.9$ & 0.5 & $0.3 ; 0.9$ \\
\hline$\geqslant 4$ glasses of wine & 2.7 & 628 & 0.6 & $0.3 ; 1.2$ & 0.6 & $0.3 ; 1.2$ \\
\hline \multicolumn{7}{|l|}{ Spirits (weekly consumption) } \\
\hline (Never drink spirits) & 2.8 & 1275 & 1.0 & - & 1.0 & - \\
\hline 1-2 glasses of spirits & 2.7 & 784 & 0.9 & $0.6 ; 1.6$ & 0.9 & $0.5 ; 1.6$ \\
\hline$\geqslant 3$ glasses of spirits & 3.5 & 371 & 1.3 & $0.7 ; 2.4$ & 1.2 & $0.6 ; 2.3$ \\
\hline \multicolumn{7}{|l|}{ Beer (weekly consumption) } \\
\hline (Never drink beer) & 3.4 & 711 & 1.0 & - & 1.0 & - \\
\hline $1-2$ beers & 2.8 & 703 & 0.8 & $0.5 ; 1.5$ & 0.8 & $0.4 ; 1.6$ \\
\hline $3-6$ beers & 2.0 & 503 & 0.6 & $0.3 ; 1.2$ & 0.6 & $0.3 ; 1.3$ \\
\hline $7-10$ beeers & 2.2 & 223 & 0.7 & $0.2 ; 1.7$ & 0.6 & $0.2 ; 1.8$ \\
\hline$\geqslant 11$ beers & 3.8 & 290 & 1.1 & $0.5 ; 2.3$ & 1.1 & $0.5 ; 2.6$ \\
\hline \multicolumn{7}{|c|}{ Cumulative number of drinks (weekly consumption) } \\
\hline (0-2 drinks) & 3.4 & 670 & 1.0 & - & 1.0 & - \\
\hline 3-5 drinks & 2.8 & 567 & 0.8 & $0.4 ; 1.6$ & 0.8 & $0.4 ; 1.6$ \\
\hline $6-12$ drinks & 1.7 & 650 & 0.5 & $0.2 ; 1.0$ & 0.5 & $0.2 ; 1.0$ \\
\hline$\geqslant 13$ drinks & 3.7 & 549 & 1.1 & $0.6 ; 2.0$ & 1.1 & $0.5 ; 2.6$ \\
\hline \multicolumn{7}{|l|}{ Tea (cups taken daily) } \\
\hline (0) & 3.2 & 1240 & 1.0 & - & 1.0 & - \\
\hline $1-2$ & 2.5 & 671 & 0.8 & $0.4 ; 1.4$ & 0.8 & $0.4 ; 1.4$ \\
\hline$\geqslant 3$ & 2.5 & 519 & 0.8 & $0.4 ; 1.5$ & 0.8 & $0.4 ; 1.5$ \\
\hline \multicolumn{7}{|l|}{ Coffee (cups taken daily) } \\
\hline$(0-3)$ & 2.9 & 732 & 1.0 & - & 1.0 & - \\
\hline $4-5$ & 2.1 & 621 & 0.7 & $0.4 ; 1.5$ & 0.7 & $0.4 ; 1.4$ \\
\hline $6-8$ & 2.8 & 679 & 1.0 & $0.5 ; 1.8$ & 1.0 & $0.5 ; 1.8$ \\
\hline$\geqslant 9$ & 4.3 & 398 & 1.5 & $0.8 ; 2.9$ & 1.6 & $0.8 ; 3.0$ \\
\hline \multicolumn{7}{|l|}{ Leisure time energy expenditure } \\
\hline (Sedentary) & 4.4 & 589 & 1.0 & - & 1.0 & - \\
\hline Ambulatory & 2.3 & 1294 & 0.5 & $0.3 ; 0.9$ & 0.5 & $0.3 ; 0.9$ \\
\hline Active & 2.6 & 547 & 0.6 & $0.3 ; 1.1$ & 0.5 & $0.3 ; 1.1$ \\
\hline
\end{tabular}

the fundus, corpus, or antrum area. Craters in the pyloric canal or in the duodenum were classified as duodenal ulcers (DUs). Scars or deformities were accepted as signs of former ulcers. Malignant ulcers were excluded.

\section{Study variables}

A self administered questionnaire was completed at both attendances. The following variables were assessed:

(i) sociodemographic factors: sex, age;

(ii) socioeconomic status ${ }^{16}$;

(iii) genetic factors: family history of PUD, Lewis blood group antigens;

(iv) lifestyle practices: tobacco smoking (cumulative tobacco consumption (g/day)—cumulative consumption of different tobacco products), alcohol (weekly consumption of beer, wine, and spirits—cumulative weekly number of drinks), coffee and tea intake (number of cups taken daily), leisure time physical activity (sedentary, ambulatory, active);

(v) medication assessed at study entry: unspecified drugs for gastrointestinal disorders, unspecified antirheumatic drugs (NSAIDs), minor and major tranquillisers, antibiotics;

(vi) medication assessed at follow up: antacids, $\mathrm{H}_{2}$ receptor antagonists, proton pump inhibitors (PPIs), ASA, acetaminophen, NSAIDs, and antibiotics.

Use of medications was categorised as never-infrequent, previous use within the past five years (daily, weekly, monthly, prophylactic treatment regimens), or current use (daily, 
Table 2 Eleven year cumulated incidence of peptic ulcer disease (PUD) in 1994 by categories of baseline exposures: medication at study entry and five years preceding follow up. Unadjusted and sex and age adjusted odds ratios (OR, 95\% confidence intervals $(\mathrm{Cl}))$

\begin{tabular}{|c|c|c|c|c|c|c|}
\hline \multirow{2}{*}{$\begin{array}{l}\text { Baseline exposure } \\
\text { (reference category) }\end{array}$} & \multicolumn{2}{|c|}{ PUD incidence } & \multicolumn{2}{|l|}{ Unadjusted } & \multicolumn{2}{|c|}{ Sex and age adjusted } \\
\hline & $\%$ & $\mathrm{n}$ & Odds ratio & $95 \% \mathrm{Cl}$ & Odds ratio & $95 \% \mathrm{Cl}$ \\
\hline \multicolumn{7}{|c|}{ Uspecified gastrointestinal drugs in 1982} \\
\hline (Never-infrequent use) & 2.4 & 2071 & 1.0 & - & 1.0 & - \\
\hline Previous use & 2.4 & 125 & 1.0 & $0.3 ; 3.2$ & 1.2 & $0.4 ; 4.0$ \\
\hline Current use & 7.3 & 232 & 3.2 & $1.8 ; 5.6$ & 3.2 & $1.7 ; 5.5$ \\
\hline \multicolumn{7}{|c|}{ Antirheumatic drug use at study entry in 1982} \\
\hline (Never-infrequent use) & 2.9 & 2156 & 1.0 & - & 1.0 & - \\
\hline Previous use & 2.6 & 190 & 0.9 & $0.4 ; 2.3$ & 0.9 & $0.3 ; 2.2$ \\
\hline Current use & 2.4 & 82 & 0.8 & $0.2 ; 3.5$ & 0.7 & $0.2 ; 3.0$ \\
\hline \multicolumn{7}{|c|}{ Antibiotic use at study entry in 1982} \\
\hline (Never-infrequent use) & 2.8 & 2402 & 1.0 & - & 1.0 & \\
\hline Previous use & 0.0 & 8 & & & & - \\
\hline Current use & 11.1 & 18 & 4.1 & $0.9 ; 18.1$ & 4.2 & $1.1 ; 16.9$ \\
\hline \multicolumn{7}{|c|}{ Major tranquilliser use at study entry in 1982} \\
\hline (Never-infrequent use) & 2.4 & 2381 & 1.0 & - & 1.0 & - \\
\hline Previous use & 0.0 & 1 & & & & \\
\hline Current use & 2.0 & 37 & 2.3 & $0.5 ; 9.9$ & 2.2 & $0.5 ; 9.6$ \\
\hline \multicolumn{7}{|c|}{ Minor tranquilliser use at study entry in 1982} \\
\hline (Never-infrequent use) & 2.1 & 2373 & 1.0 & - & 1.0 & - \\
\hline Previous use & 3.6 & 28 & 1.7 & $0.2 ; 12.9$ & 1.8 & $0.2 ; 13.4$ \\
\hline Current use & 8.5 & 118 & 4.3 & $2.1 ; 8.7$ & 4.4 & $2.1 ; 9.2$ \\
\hline \multicolumn{7}{|c|}{ Antacid use in the past 5 years } \\
\hline (Never-infrequent use) & 2.3 & 2367 & 1.0 & - & 1.0 & - \\
\hline Previous use & 9.5 & 21 & 4.4 & $1.0 ; 19.5$ & 4.1 & $0.9 ; 18.2$ \\
\hline Current use & 6.5 & 31 & 2.9 & $0.7 ; 12.5$ & 2.8 & $0.7 ; 12.3$ \\
\hline \multicolumn{7}{|c|}{$\mathrm{H}_{2}$ receptor antagonist use in the past 5 years } \\
\hline (Never-infrequent use) & 1.7 & 2371 & 1.0 & - & 1.0 & - \\
\hline Previous use & 34.6 & 26 & 30.1 & $12.7 ; 71.5$ & 30.5 & $12.6 ; 74.0$ \\
\hline Current use & 40.9 & 22 & 39.3 & $15.9 ; 97.2$ & 38.6 & $15.4 ; 97.2$ \\
\hline \multicolumn{7}{|c|}{ Proton pump inhibitor use in the past 5 years } \\
\hline (Never-infrequent use) & 2.2 & 2397 & 1.0 & - & 1.0 & - \\
\hline Previous use & 33.3 & 9 & 22.1 & $5.4 ; 90.9$ & 20.1 & $4.8 ; 83.9$ \\
\hline Current use & 30.0 & 10 & 19.0 & $4.8 ; 75.4$ & 16.6 & $4.1 ; 67.0$ \\
\hline \multicolumn{7}{|c|}{ NSAID use in the past 5 years } \\
\hline (Never-infrequent use) & 2.5 & 2256 & 1.0 & - & 1.0 & - \\
\hline Previous use & 0.0 & 33 & & & & \\
\hline Current use & 2.3 & 130 & 0.9 & $0.3 ; 3.0$ & 0.9 & $0.3 ; 3.0$ \\
\hline \multicolumn{7}{|l|}{ ASA use in the past 5 years } \\
\hline (Never-infrequent use) & 2.4 & 2305 & 1.0 & - & 1.0 & - \\
\hline Previous use & 0.0 & 1 & & & & \\
\hline Current use & 2.7 & 113 & 1.1 & $0.3 ; 3.6$ & 0.9 & $0.3 ; 3.1$ \\
\hline \multicolumn{7}{|c|}{ Paracetamol use in the past 5 years } \\
\hline (Never-infrequent use) & 2.3 & 2159 & 1.0 & - & 1.0 & - \\
\hline Previous use & 0.0 & 9 & & & & \\
\hline Current use & 4.0 & 251 & 1.8 & $0.9 ; 3.6$ & 1.8 & $0.9 ; 3.7$ \\
\hline \multicolumn{7}{|c|}{ Antibiotic use in the past 5 years } \\
\hline (Never-infrequent use) & 2.4 & 2390 & 1.0 & - & 1.0 & - \\
\hline Previous use & 0.0 & 1 & & & & \\
\hline Current use & 7.4 & 27 & 3.3 & $0.8 ; 14.2$ & 3.2 & $0.7 ; 13.7$ \\
\hline
\end{tabular}

weekly, monthly, prophylactic treatment regimens). $H$ pylori infection status was assessed as anti-Hp IgG status at study entry and follow up, and as changes in anti-Hp IgG status within the observation period.

\section{Statistical methods}

The SPSS statistical package for Windows was used. ${ }^{17}$ The incidence of PUD was used as the dependent variable in a series of logistic regression analyses using forward stepwise inclusion. All variables that improved the fit of sex and age adjusted models were incorporated into a final logistic regression model together with possible confounders (multivariate adjusted ORs). As some variables were interrelated, different final models were constructed. Exposure status at study entry (baseline exposure status) was assumed to reflect risk factor exposure at the time of ulcer diagnosis.

Interaction terms were fitted into the analyses if effect modification was suspected. If effect modification was demonstrated, separate analyses were made for each stratum-for example, anti-Hp positive/borderline and anti$H p$ negative participants.

The population attributable risk per cent (PAR\%) was calculated from the following equation:

$$
P A R \%=(\operatorname{Pe}(O R-1) / P e(O R-1)+1) \times 100
$$

where Pe is the prevalence of the exposure at baseline and OR is the multivariate adjusted risk of PUD. ${ }^{18}$ Level of significance was set at $5 \%$.

\section{RESULTS}

\section{Response patterns at follow up}

Members of the original cohort who failed to attend the follow up examination (non-responders) differed from those who attended follow up (responders) by being older (odds ratio 2.7 
Table 3 Final logistic regression model for all ulcers Helicobacter pylori infection, lifestyle practices, and medication at study entry $\ddagger$ lodds ratios and $95 \%$ confidence intervals) *

\begin{tabular}{|c|c|c|}
\hline \multirow{2}{*}{$\begin{array}{l}\text { Baseline exposure } \\
\text { (reference category) }\end{array}$} & \multicolumn{2}{|c|}{ Multivariate adjusted } \\
\hline & Odds ratio & $95 \% \mathrm{Cl}$ \\
\hline \multicolumn{3}{|l|}{ Anti-Hp lgG sero-status } \\
\hline (Seronegative) & 1.0 & - \\
\hline Borderline & 3.4 & $1.8 ; 7.3$ \\
\hline Seropositive & 4.3 & $2.2 ; 8,3$ \\
\hline \multicolumn{3}{|c|}{ Anti-Hp changes within the observation period } \\
\hline (Persistently seronegative) & 1.0 & - \\
\hline Persistently borderline & 2.2 & $0.9 ; 5.3$ \\
\hline Persistently seropositive & 3.6 & $1.8 ; 7.4$ \\
\hline Changes & 4.8 & $2.3 ; 10,0$ \\
\hline \multicolumn{3}{|c|}{ Cumulative tobacco consumption } \\
\hline (Never-smoker) & 1.0 & - \\
\hline Former smoker & 2.0 & $0.7 ; 5.9$ \\
\hline $1-14.99 \mathrm{~g} /$ day & 4.0 & $1.6 ; 10.4$ \\
\hline $15-24.99 \mathrm{~g} /$ day & 4.5 & $1.6 ; 11.0$ \\
\hline$\geqslant 25 \mathrm{~g} /$ day & 3.0 & $0.8 ; 11.9$ \\
\hline \multicolumn{3}{|c|}{ Cumulative number of cigarettes smoked daily $\dagger$} \\
\hline 0 & 1.0 & - \\
\hline $1-9$ cigarettes & 1.5 & $0.6 ; 3.5$ \\
\hline $10-14$ cigarettes & 1.3 & $0.5 ; 3.1$ \\
\hline $15-20$ cigarettes & 2.0 & $1.0 ; 4.1$ \\
\hline$\geqslant 21$ cigarettes & 2.5 & $0.9 ; 6.9$ \\
\hline \multicolumn{3}{|l|}{ Wine (weekly consumption) } \\
\hline (Never drink wine) & 1.0 & - \\
\hline $1-3$ glasses of wine & 0.5 & $0.3 ; 1.2$ \\
\hline \multirow{2}{*}{\multicolumn{3}{|c|}{$\begin{array}{l}24 \text { glasses or Wine } \\
\text { Spirits (weekly consumption) }\end{array}$}} \\
\hline & & \\
\hline (Never drink spirits) & 1.0 & - \\
\hline $1-2$ glasses of spirits & 1.8 & $0.9 ; 3.6$ \\
\hline$\geqslant 3$ glasses of spirits & 1.8 & $0.8 ; 4.3$ \\
\hline \multicolumn{3}{|c|}{ Cumulated number of drinks (weekly consumption) } \\
\hline (0-2 drinks) & 1.0 & - \\
\hline $3-5$ drinks & 1.2 & $0.6 ; 2.5$ \\
\hline $6-12$ drinks & 0.5 & $0.2 ; 1.1$ \\
\hline$\geqslant 13$ drinks & 0.9 & $0.4: 1.8$ \\
\hline \multicolumn{3}{|c|}{ Leisure time energy expenditure } \\
\hline (Sedentary) & 1.0 & - \\
\hline Ambulatory & 0.5 & $0.3 ; 0.9$ \\
\hline Active & 0.8 & $0.4 ; 1.6$ \\
\hline \multicolumn{3}{|c|}{ Uspecified gastrointestinal drugs at study entry in 1982} \\
\hline (Never-infrequent use) & 1.0 & - \\
\hline Previous use & 1.2 & $0.4 ; 4.3$ \\
\hline Current use & 3.2 & $1.7 ; 6.2$ \\
\hline \multicolumn{3}{|c|}{ NSAID use at study entry in 1982} \\
\hline (Never-infrequent use) & 1.0 & - \\
\hline Previous use & 0.8 & $0.3 ; 2.3$ \\
\hline Current use & 0.4 & $0.1 ; 2.3$ \\
\hline \multicolumn{3}{|c|}{ Minor tranquillisers use at study entry in 1982} \\
\hline (Never-infrequent use) & 1.0 & - \\
\hline Previous use & 1.9 & $0.2 ; 15.0$ \\
\hline Current use & 3.0 & $1.4 ; 6.6$ \\
\hline
\end{tabular}

*Different logistic regression models were constructed as some variables were inter-related and could not be fitted into the same model. were inter-related and could not
tIn former and current smokers.

$\ddagger$ Medication: daily, weekly, or monthly previous or current use.

(95\% confidence interval $2.2 ; 3.4)$ ), by emanating from poor socioeconomic strata $(1.9(1.4 ; 2.4))$, by being heavy smokers $(2.4(1.9 ; 3.0))$, and by being psychologically vulnerable $(1.5$ $(1.2 ; 2.0))$. H pylori infection status did not affect the response pattern.

\section{Peptic ulcer incidence and diagnostic verification}

A total of 71 first time diagnosed ulcers were eligible for analyses. The 11 year cumulative incidence proportion was $2.9 \%(95 \%$ confidence interval $2.2 ; 3.6)$-that is, $1.6 \%(1.1$; $2.1), 1.3 \%(0.8 ; 1.7)$, and $0.04 \%(0.02 ; 0.07)$ for DU $(n=39), G U$ $(n=31)$, and combined ulcers $(n=1)$, respectively. Sixteen ulcers had been verified by barium meal examination, 45 ulcers were diagnosed by upper endoscopy, five cases of perforated ulcers were found at surgery, and four ulcers were verified by a combination of different diagnostic methods.

\section{$\boldsymbol{H}$ pylori infection at baseline and follow up}

Seropositive or borderline increased anti-Hp IgG levels at study entry significantly increased the likelihood of developing an ulcer (table 1). There were no cases of PUD among patients who became infected with $H$ pylori within the observation period $(n=14)$ but those who had a fourfold decrease in baseline anti-Hp IgG levels suggesting loss of the infection $(n=44)$ were more likely than those who remained seropositive to report an ulcer. A high number of PUD cases was seen in those who showed variations in antibody status (table 1).

Fifty two $(74.3 \%)$ ulcers were diagnosed in patients with seropositive or borderline increased anti-Hp IgG whereas the remaining 18 ulcers $(25.7 \%)$ were seen in IgG seronegative individuals. The seroprevalence of $H$ pylori infection was $87.2 \%$ in DU (IgG seropositive 56.4\%/IgG borderline 30.8\%) and $60.0 \%$ in GU patients (IgG seropositive 13.3\%/IgG borderline 46.7\%).

\section{Lifestyle practices at baseline}

Tobacco smoking caused a significant increase in the risk of developing an ulcer (table 1). Dose-response relationships were seen between PU incidence and cumulative tobacco consumption and cumulative number of cigarettes. The low number of ulcers among users of other tobacco products did not allow separate analyses.

A tendency towards an increase in the PUD incidence proportion with the number of consumed drinks was observed resulting in a "U shaped" relation. The nadir of the distribution was 6-12 drinks weekly. This relationship was due to a low number of ulcers among people who drank moderate amounts of wine. Intake of beer and spirits did not affect the overall ulcer incidence proportion.

Although a high number of PUD cases was reported in patients who consumed large amounts of coffee, ulcer incidence in general did not relate to the use of coffee and tea at study entry. A possible protective effect of moderate to high leisure time energy expenditure against PUD was seen.

\section{Drug consumption}

Drug consumption at study entry

Current use of antibiotics, unspecified gastrointestinal drugs, and minor tranquillisers was associated with high ulcer incidence rates at follow up (table 2). The use of antirheumatic drugs did not relate to ulcer incidence.

\section{Drug consumption at follow up}

As could be expected, the use of antacids, $\mathrm{H}_{2}$ receptor antagonists, and PPIs was more frequent among those who had a first time diagnosed peptic ulcer.

\section{Multivariate logistic regression analyses}

In addition to the variables in question, all final models were controlled for demographic, psychosocial, and genetic factors.

\section{Final model for all ulcers}

To preserve statistical power regression analyses were initially done for all ulcers together. The following baseline exposures were associated with an increased risk of reporting a PU at follow up: seropositive or borderline increased anti-Hp IgG, tobacco smoking, current use of minor tranquillisers, and current use of unspecified gastrointestinal drugs (table 3). The dose-response relationship between cumulative tobacco consumption and PU incidence persisted in multivariate analyses. Moderate leisure time energy expenditure reduced the likelihood of PUD. Regression models, which included different alcohol containing beverages instead of cumulative number of drinks, did not yield further information. No other 


\begin{tabular}{|c|c|c|c|c|c|c|c|c|}
\hline \multirow{3}{*}{$\begin{array}{l}\text { Baseline exposure } \\
\text { (reference category) } \neq\end{array}$} & \multicolumn{4}{|c|}{ Anti-Hp lgG positive or borderline participants } & \multicolumn{4}{|c|}{ Duodenal ulcert } \\
\hline & \multicolumn{2}{|c|}{ PUD incidence } & \multicolumn{2}{|c|}{ Multivariate adjusted* } & \multicolumn{2}{|c|}{ PUD incidence } & \multicolumn{2}{|c|}{ Multivariate adjusted* } \\
\hline & $\%$ & $n$ & Odds ratio & $95 \% \mathrm{Cl}$ & $\%$ & $\mathrm{n}$ & Odds ratio & $95 \% \mathrm{Cl}$ \\
\hline \multicolumn{9}{|l|}{ Anti-Hp lgG sero-status } \\
\hline (Seronegative) & & & & & 0.4 & 1400 & 1.0 & - \\
\hline Borderline & & & & & 2.7 & 442 & 6.0 & $1.7 ; 20.1$ \\
\hline Seropositive & & & & & 4.0 & 544 & 16.0 & $5.2 ; 49.3$ \\
\hline \multicolumn{9}{|c|}{ Cumulative tobacco consumption $†$} \\
\hline (Never-smoker) & 1.1 & 270 & 1.0 & - & & & & \\
\hline Former smoker & 3.1 & 225 & 4.0 & $0.8 ; 20.8$ & & & & \\
\hline $1-14.99 \mathrm{~g} /$ day & 9.6 & 239 & 12.7 & $2.8 ; 56.8$ & & & & \\
\hline $15-24.99 \mathrm{~g} /$ day & 7.9 & 215 & 8.5 & $0.4 ; 25.1$ & & & & \\
\hline$\geqslant 25 \mathrm{~g} /$ day & 3.6 & 55 & 3.2 & $0.8 ; 11.9$ & & & & \\
\hline \multicolumn{9}{|c|}{ Cumulative number of cigarettes smoked daily } \\
\hline 0 & 2.7 & 403 & 1.0 & - & 0.6 & 975 & 1.0 & - \\
\hline 1-9 cigarettes & 5.4 & 168 & 2.4 & $0.9 ; 6.4$ & 1.4 & 368 & 2.6 & $0.7 ; 9.2$ \\
\hline $10-14$ cigarettes & 6.8 & 148 & 2.3 & $0.9 ; 6.4$ & 2.2 & 364 & 3.6 & $1.1 ; 12.1$ \\
\hline $15-20$ cigarettes & 7.6 & 224 & 2.9 & $1.2 ; 6.8$ & 2.9 & 548 & 5.0 & $1.8 ; 14.4$ \\
\hline$\geqslant 21$ cigarettes & 8.2 & 61 & 2.5 & $0.7 ; 9.0$ & 3.8 & 131 & 7.7 & $2.0 ; 29.0$ \\
\hline \multicolumn{9}{|l|}{ Wine (weekly consumption) } \\
\hline (Never drink wine) & 7.2 & 335 & 1.0 & - & 2.5 & 676 & 1.0 & - \\
\hline 1-3 glasses of wine & 3.6 & 440 & 0.5 & $0.2 ; 1.2$ & 1.4 & 1099 & 0.5 & $0.2 ; 1.2$ \\
\hline$\geqslant 4$ glasses of wine & 5.2 & 229 & 0.6 & $0.3 ; 1.5$ & 1.3 & 611 & 0.4 & $0.1 ; 1.2$ \\
\hline \multicolumn{9}{|l|}{ Spirits (weekly consumption) } \\
\hline (Never drink spirits) & 4.8 & 547 & 1.0 & - & 1.5 & 1251 & 1.0 & - \\
\hline 1-2 glasses of spirits & 5.1 & 311 & 2.4 & $1.1 ; 5.4$ & 1.6 & 770 & 1.7 & $0.8 ; 4.0$ \\
\hline$\geqslant 3$ glasses of spirits & 6.8 & 146 & 1.8 & $0.7 ; 4.4$ & 2.5 & 365 & 1.7 & $0.7 ; 4.6$ \\
\hline \multicolumn{9}{|c|}{ Leisure time energy expenditure } \\
\hline (Sedentary) & 8.8 & 239 & 1.0 & - & 2.4 & 574 & 1.0 & - \\
\hline Ambulatory & 4.0 & 524 & 0.3 & $0.2 ; 0.7$ & 1.4 & 1273 & 0.8 & $0.4 ; 1.8$ \\
\hline Active & 4.1 & 241 & 0.6 & $0.2 ; 1.4$ & 1.5 & 539 & 1.2 & $0.4 ; 3.2$ \\
\hline \multicolumn{9}{|c|}{$\begin{array}{l}\text { Uspecified gastrointestinal drugs at study } \\
\text { entry }\end{array}$} \\
\hline (Never-infrequent use) & 4.4 & 856 & 1.0 & _- & 1.4 & 2037 & 1.0 & _- \\
\hline Previous use & 4.5 & 44 & 1.3 & $0.3 ; 6.0$ & 0.8 & 123 & 0.5 & $0.1 ; 4.2$ \\
\hline Current use & 11.7 & 103 & 3.0 & $1.4 ; 6.5$ & 4.5 & 224 & 3.4 & $1.5 ; 7.4$ \\
\hline \multicolumn{9}{|c|}{ Minor tranquilliser use at study entry in 1982} \\
\hline (Never-infrequent use) & 3.9 & 924 & 1.0 & & 1.4 & 2212 & 1.0 & - \\
\hline Previous use & 5.9 & 17 & 2.9 & $0.3 ; 24.9$ & 0.0 & 27 & 0.1 & - \\
\hline Current use & 12.7 & 55 & 2.8 & $1.1 ; 7.3$ & 4.5 & 107 & 2.6 & $0.8 ; 7.5$ \\
\hline
\end{tabular}

*All odds ratios are mutually adjusted and adjusted for age, sex, and psychosocial factors.

$\dagger$ All duodenal ulcer patients were former or current smokers.

†Blank cells indicate that the variable was inapplicable.

factors including age, sex, genetic factors, and NSAID intake were shown to affect PUD incidence proportions.

\section{Effect modification}

A significant effect modification was demonstrated between $H$ pylori status and tobacco smoking (odds ratio 70.9) suggesting that smoking only affects ulcer diathesis in patients infected with $H$ pylori. A six point ordinal variable that combined tobacco smoking and anti-Hp IgG status was constructed. Patients who were current tobacco smokers at study entry and had increased IgG antibodies to $H$ pylori (seropositive or borderline) suffered an almost sevenfold increased risk of developing an ulcer compared with anti- $H p$ negative never smokers (odds ratio 6.6 (95\% confidence interval $2.3 ; 19.0)$ ). No other significant interactions could be demonstrated. To account for this effect, modification stratum specific analyses by $H$ pylori infection status were done.

\section{Final model for anti-Hp seropositive and borderline individuals}

Tobacco smoking, weekly consumption of spirits, and use of unspecified gastrointestinal drugs or minor tranquillisers at study entry were associated with higher PUD incidence rates in those with seropositive or borderline increased IgG antibodies to $H$ pylori (table 4). In contrast, moderate leisure time physical activity seemed to protect against ulcer develop- ment in this subgroup. An insignificant protective effect of wine drinking on ulcer development was noted.

Final model for anti-Hp seronegative individuals

Only $18 H$ pylori seronegative ulcers were available for analyses. Although tobacco smoking, use of minor tranquillisers, and tea consumption were related to PUD incidence in this subgroup, none of these associations reached significance.

\section{Final model for duodenal ulcers}

All duodenal ulcer patients were either former smokers or current smokers. Among former and current smokers there was a marked dose-response relationship between the number of cigarettes smoked daily and DU incidence (table 4). Increased anti-Hp IgG levels and use of unspecified gastrointestinal drugs at study entry were associated with an increase in the likelihood of developing a DU within the observation period.

\section{Final model for gastric ulcers}

Borderline increased IgG antibodies to $H$ pylori and use of minor tranquillisers at study entry increased the odds of having a gastric ulcer whereas leisure time energy expenditure seemed to reduce gastric ulcer risk (table 5). The use of NSAIDs did not increase the risk of GU. 
Table 5 Final logistic regression model for gastric ulcer disease; 11 year cumulative incidence of peptic ulcer disease (PUD). Odds ratios and $95 \%$ confidence intervals $(\mathrm{Cl})^{*}$

\begin{tabular}{|c|c|c|c|c|}
\hline \multirow[b]{3}{*}{ Baseline exposure (reference category) } & \multicolumn{4}{|c|}{ Gastric ulcer } \\
\hline & \multicolumn{2}{|c|}{ PUD incidence } & \multicolumn{2}{|c|}{ Multivariate adjusted* } \\
\hline & $\%$ & $n$ & Odds ratio & $95 \% \mathrm{Cl}$ \\
\hline \multicolumn{5}{|l|}{ Anti-Hp lgG sero-status } \\
\hline (Seronegative) & 0.9 & 1407 & 1.0 & - \\
\hline Borderline & 3.2 & 444 & 2.7 & $1.2 ; 6.6$ \\
\hline Seropositive & 0.8 & 526 & 0.7 & $0.2 ; 2.4$ \\
\hline \multicolumn{5}{|l|}{ Leisure time energy expenditure } \\
\hline (Sedentary) & 2.1 & 572 & 1.0 & - \\
\hline Ambulatory & 1.0 & 1268 & 0.4 & $0.1 ; 0.9$ \\
\hline Active & 1.1 & 537 & 0.7 & $0.2 ; 2.1$ \\
\hline \multicolumn{5}{|c|}{ Uspecified gastrointestinal drugs at study entry } \\
\hline (Never-infrequent use) & 1.0 & 2029 & 1.0 & - \\
\hline Previous use & 1.6 & 124 & 2.1 & $0.5 ; 10.0$ \\
\hline Current use & 3.6 & 222 & 3.0 & $1.1 ; 8.1$ \\
\hline \multicolumn{5}{|l|}{ Minor tranquilliser use at study entry } \\
\hline (Never-infrequent use) & 0.8 & 223 & 1.0 & - \\
\hline Previous use & 3.6 & 28 & 4.0 & $0.5 ; 32.5$ \\
\hline Current use & 4.5 & 112 & 3.4 & $1.2: 10.0$ \\
\hline \multicolumn{5}{|l|}{ NSAID use at study entry } \\
\hline (Never-infrequent use) & 1.4 & 2079 & 1.0 & - \\
\hline Previous use & 0.5 & 185 & 0.4 & $0.1 ; 2.8$ \\
\hline Current use & 1.2 & 80 & 0.7 & $0.1 ; 6.0$ \\
\hline
\end{tabular}

Table 6 Population attributable risk per cent (PAR\%) for different risk factors for peptic ulcer disease (PUD) in 2416 Danish adults with no previous history of ulcer disease

\begin{tabular}{llll}
\hline Variable (baseline exposure) & $\mathrm{Pe}^{*}$ & Odds ratiot & PAR\% \\
\hline Seropositive for lgG antibodies to H pylori & 0.24 & 4.3 & 44.2 \\
Current tobacco smoking & 0.56 & 3.8 & 61.0 \\
Poor socioeconomic status & 0.12 & 2.9 & 18.4 \\
Current use of minor tranquillisers & 0.06 & 2.4 & 8.2 \\
\hline \multirow{2}{*}{ *Prevalence of exposure to variable at study entry. } \\
†Multivariate adjusted odds ratios. Odds ratios for \\
reported elsewhere.
\end{tabular}

\section{Aetiological fractions}

Table 6 shows the attributable risk per cents for baseline exposures that were shown to increase the risk of first time diagnosed PUs significantly, irrespective of ulcer site. Because of a high prevalence of tobacco smoking, smoking accounted for more than $60 \%$ of all ulcer cases in this cohort whereas $44 \%$ of ulcer cases were attributable to $H$ pylori infection. The remaining risk factors accounted for approximately $25 \%$ of the variance.

\section{DISCUSSION}

Ours is one of the first population based prospective studies in the $H$ pylori era which has examined the impact of several risk factors for PUD, including $H$ pylori. The most important findings were that $H$ pylori infection, tobacco smoking, and use of minor tranquillisers were the main risk factors for PUD in this population of Danish adults. Leisure time energy expenditure reduced the likelihood of PUD. When analyses were confined to $H$ pylori positive individuals, wine drinking showed a possible protective effect against PUD whereas intake of spirits increased ulcer risk. Use of NSAIDs did not affect GU or DU rates. A significant effect modification was demonstrated between tobacco smoking and $H$ pylori infection, suggesting that tobacco smoking only increases PU risk in those who harbour H pylori.

Approximately $25 \%$ of all incident ulcers were found in those with no serological signs of $H$ pylori infection. Serology usually overestimates the prevalence of active $H$ pylori infection. The serology used in this study measures low molecular weight $H$ pylori antigens that are less strongly expressed in patients with gastric atrophy. The prevalence of infection may therefore be slightly underestimated in older people. The low specificity of the serology implies a high number of anti- $\mathrm{Hp}$ false positive results. This misclassification weakens the impact of $H$ pylori infection on ulcer incidence. As the prevalence of $H$ pylori infection is low in Denmark, ${ }^{19}$ the proportion of ulcers that can be attributed to $H$ pylori infection is likely to be higher in countries where $H$ pylori infection is more common.

In contrast with data from the USA, ${ }^{7}$ tobacco smoking seems to be a more important risk factor for PUD than $H$ pylori infection in Denmark. ${ }^{20}{ }^{21}$ Recent studies have suggested that tobacco smoking causes PU only if $H$ pylori infection is present. $^{22-24}$ Our findings support this notion but tobacco smoking remained an independent risk factor for PUD despite control for $H$ pylori infection status. For that reason, we believe that ulcer patients should be advised to cease smoking irrespective of $H$ pylori infection status. ${ }^{25}$

The association between coffee drinking and PUD is controversial. ${ }^{26}$ The prospective nature of this study should prevent bias resulting from changes in coffee drinking habits due to medical advice. ${ }^{27}{ }^{28}$ Still, it is possible that ulcer patients may have reduced their coffee intake prior to ulcer diagnosis because of abdominal discomfort. 
Recent studies have shown a significant reduction in duodenal ulcer risk in American men who exercise regularly. ${ }^{29}$ Older studies suggest that physical inactivity increases the likelihood of ulcer disease. ${ }^{30}{ }^{31}$ Moderate energy expenditure was shown to reduce the overall likelihood of ulcer disease in this study. Possible mechanisms could include a decrease in gastric acid secretion, lower levels of stress, and differences in dietary factors. ${ }^{32}$

$H$ pylori infection rates in DU disease are declining. ${ }^{33}{ }^{34}$ The seroprevalence of $H$ pylori infection was $87.2 \%$ in DU patients when those with borderline increased anti-Hp IgG were considered infected. This value overestimates the true prevalence as some patients with borderline increased IgG antibodies are uninfected. When this subgroup was excluded, the seroprevalence of $H$ pylori infection was $56.4 \%$ in DU patients and even lower in GU patients. The present data therefore support the notion that the prevalence of $H$ pylori infection in DU patients is lower than previously thought and emphasises that eradication therapy should not be initiated without prior verification of the infection. ${ }^{35}$

The absence of an association between the use of NSAIDs and PUD incidence is surprising. The link between PUD and NSAID consumption is most pronounced in elderly patients who present with bleeding GUs. Possible explanations for our findings may be limited statistical power due to a low number of first time diagnosed GUs, few complicated ulcers, a relatively young cohort whose maximum age was 70 years, or invalid data on the use of NSAIDs at study entry. It is also possible that the impact of NSAIDs could be less marked in the general population who primarily suffers from uncomplicated ulcers.

Although the present analyses were adjusted for psychological vulnerability, the relationship between minor tranquillisers and ulcer incidence could simply be explained by differences in personality traits between ulcer patients and other subjects. ${ }^{36}$ PUD was previously considered a psychosomatic disease and tranquillisers may have been used to treat ulcer patients. As more effective treatments have become available within the last 20 years, this approach is unlikely to explain the present findings.

In this study, inferences were made between baseline exposure to possible risk factors and the subsequent development of a peptic ulcer. No data were available on whether the participant was exposed to the risk factor in question at the time of ulcer formation. Although most patients retain their lifestyle habits until disease develops, it is likely that some may have ceased risk factor behaviour during the observation period while others may have been exposed to a possible risk factor not reported at study entry. This non-differential misclassification will weaken possible relationships.

Moderate alcohol intake may reduce the likelihood of ulcer disease $^{323738}$ but large scale population based studies have failed to confirm this association. ${ }^{45}$ Intake of spirits increased the risk of PU in patients with increased anti- $\mathrm{Hp}$ IgG in this study. Excessive alcohol consumption has been shown to increase the risk of PUD. ${ }^{39}$ Wine and beer drinking is associated with lower rates of $H$ pylori infection. ${ }^{38} 4041$ Biological mechanisms that could explain a possible beneficial effect of wine drinking on $\mathrm{H}$ pylori infection and ulcer formation have been reported ${ }^{42}{ }^{43}$ Wine drinking could also be a marker for an overall healthier lifestyle. ${ }^{44}$

In conclusion, the aetiology of PUD is multifactorial. Tobacco smoking, $H$ pylori infection, and use of minor tranquillisers but not NSAIDs are the main determinants to PUD in this cohort of Danish adults. Alcohol containing beverages in general did not relate to PUD incidence but intake of spirits was shown to increase the risk of PU in patients with increased anti-Hp IgG. Physical activity on the other hand reduced the risk of PUD in this subgroup.

\section{ACKNOWLEDGEMENTS}

This study was supported by the Ingeborg Roikjer Foundation (9043), the Danish Health Insurance Foundation (11/099-95), the Danish Medical research Council (12-1844-1), the Else and Mogens Wedell-Wedellsborg Foundation (6686-1), and the Jakob and Olga Madsen Foundation

\section{Authors' affiliations}

S Rosenstock, T Jørgensen, Copenhagen County Centre for Preventive Medicine, Glostrup University Hospital, Building 8.7. Nordre Ringvej, DK 2600 Glostrup, Denmark

O Bonnevie, Department of Medicine I, Bispebjerg Hospital, Bispebjerg Bakke 23, DK 2400, Copenhagen, Denmark

L Andersen, Department of Infectious Hygiene 5222, Rigshospitalet, Blegdamsvej 3, DK 2100, Copenhagen, Denmark

\section{REFERENCES}

1 Anda RF, Williamson DF, Escobedo LG, et al. Self-perceived stress and the risk of peptic ulcer disease. A longitudinal study of US adults. Arch Intern Med 1992;152:829-33.

2 Everhart JE, Byrd-Holt D, Sonnenberg A. Incidence and risk factors for self-reported peptic ulcer disease in the United States. Am J Epidemiol 1998;147:529-36

3 Cheng Y, Macera CA, Davis DR, et al. Does physical activity reduce the risk of developing peptic ulcers? Br J Sports Med 2000;34:116-21.

4 Johnsen R, Førde OH, Straume G, et al. Aetiology of peptic ulcer: a prospective population study in Norway. J Epidemiol Community Health 1994:48: $156-60$

5 Kato I, Nomura AMY, Stemmermann GN, et al. A prospective study of gastric and duodenal ulcer and its relation to smoking, alcohol and diet. Am J Epidemiol 1992;135:521-30.

6 Aldoori WH, Giovannucci EL, Stampfer M, et al. A prospective study of alcohol, smoking, caffeine, and the risk of duodenal ulcer in men. Epidemiology 1997;8:420-4.

7 Kurata JH, Nogawa AN. Meta-analysis of risk factors for peptic ulcer. Nonsteroidal antiinflammatory drugs, Helicobacter pylori, and smoking. J Clin Gastroenterol 1997;24:2-17.

8 Mégraud F, Brassens-Rabbé M-P, Denis F, et al. Seroepidemiology of Campylobacter pylori infection in various populations. J Clin Microbiol 1989;27:1870-3.

9 Graham DY, Malaty HM, Go MF. Are there susceptible hosts to Helicobacter pylori infection? Scand J Gastroenterol 1994;29/suppl 205):6-10.

10 Schlemper RJ, Van Der Werf SDJ, Vandenbroucke JP, et al. Risk factors of peptic ulcer disease: Different impact of Helicobacter pylori in Dutch and Japanese populations? J Gastroenterol Hepatol 1996;1 1:825-31.

11 Rosenstock SJ, Jørgensen T. Prevalence and incidence of peptic ulcer disease in a Danish county-a prospective cohort study. Gut 1995;36:819-24

12 Rosenstock SJ, Jørgensen T, Andersen LP, et al. Seroconversion and seroreversion in lgG antibodies to Helicobacter pylori: a serology based prospective cohort study. J Epidemiol Community Health 2000:54:444-50.

13 Andersen LP, Raskov H-H, Elsborg L, et al. Prevalence of antibodies against heat-stable antigens from Helicobacter pylori in patients with dyspeptic symptoms and normal persons. APMIS 1992;100:779-89.

14 Andersen LP, Espersen F, Souckova A, et al. Isolation and preliminary evaluation of a low molecular (LMW) antigen preparation for improved detection of Helicobacter pylori lgG antibodies. Clin Diagnostic Lab Immunol 1995;2:156-9.

15 Andersen LP, Kiilerich S, Pedersen G, et al. An analysis of seven different methods to diagnose Helicobacter pylori infections. Scand Gastroenterol 1998;33:24-30.

16 Hansen H. Living conditions in Denmark. Compendium of statistics. Copenhagen: Danmarks Statistik, 1984.

17 Norusis MJ. SPSS for Windows. Advanced statistics release 6.0. Chicago: SPSS Inc, 1993:2-30.

18 Hennekens $\mathrm{CH}$, Buring JE. Epidemiology in medicine. Boston/Toronto: Little, Brown and Company, 1987.

19 Andersen LP, Rosenstock SJ, Bonnevie O, et al. Seroprevalence of immunoglobulin $G, M$, and $A$ antibodies to Helicobacter pylori in an unselected Danish population. Am J Epidemiol 1996;143:1 157-64.

20 Andersen IB, Jørgensen T, Bonnevie O, et al. Smoking and alcohol intake as risk factors for bleeding and perforated peptic ulcers: a population-based cohort study. Epidemiology 2000;11:434-9.

21 Kirchhoff $M$, Hansen $B$. Changes in smoking habits in a Danish population from 1983 to 1988 (abstract in English). Ugeskr Læger 1995; 157:3457-61

22 Chan FKL, Sung JJY, Lee YT, et al. Does smoking predispose to peptic ulcer relapse after eradication of Helicobacter pylori? Am J Gastroenterol 1997:92:442-5.

23 Borody T, George L, Brandl S, et al. Smoking does not contribute to duodenal ulcer relapse after Helicobacter pylori eradication. Am J Gastroenterol 1992;87:1390-3

24 Stack WA, Atherton JC, Hawkey GM, et al. Interactions between Helicobacter pylori and other risk factors for peptic ulcer bleeding. Aliment Pharmacol Ther 2002;16:497-506. 
25 Parasher G, Eastwood GL. Smoking and peptic ulcer in the Helicobacter pylori era. Eur J Gastroenterol Hepatol 2000;1 12:843-53.

26 Suadicani P, Hein HO, Gyntelberg F. Genetic and life-style determinants of peptic ulcer. A study of 3387 men aged 54 to 74 years: The Copenhagen Male Study. Scand J Gastroenterol 1999:34:12-17.

27 Eisig JN, Zaterka S, Massuda HK, et al. Coffee drinking in patients with duodenal ulcer and a control population. Scand J Gastroenterol 1989;24:796-8.

28 Kang JY, Tay HH, Guan R. Chronic upper abdominal pain: site and radiation in various structural and functional disorders and the effect of various foods. Gut 1992;33:743-8.

29 Cheng Y, Macera CA, Blair SN. Physical acitivity and peptic ulcers. Does physical activity reduce the risk of developing peptic ulcers? West J Med 2000;173:101-7.

30 Paffenberger RS, Wing AL, Hyde RT. Chronic disease in former college students XIII. Early precursors of peptic ulcer. Am J Epidemiol 1974; 100:397-15

31 Chuong JJH, Fisher RL, Chuong RLB, et al. Incidence, risk factors, and predictive value of plasma pepsinogen. Dig Dis Sci 1986;31:1178-84.

32 Aldoori WH, Giovannucci EL, Stampfer M, et al. Prospective study of diet and the risk of duodenal ulcer in men. Am J Epidemiol 1997:145:42-50.

33 Ciociola AA, McSorley DJ, Turner K, et al. Helicobacter pylori infection rates in duodenal ulcer patients in the United States may be lower than previously estimated. Am J Gastroenterol 1999;94:1834-40.

34 Juul KV, Østergård Thomsen O, Nissen A, et al. National surveillance of Helicobater pylori eradication therapy in Denmark. Results from a registration of 34,582 prescriptions. Scand J Gastroenterol 1998; 33:928-32.
35 Bytzer P, Teglbjærg PS, Danish Ulcer Study Group. Helicobacter pylori-negative duodenal ulcers: prevalence, clinical characteristics, and prognosis-results from a randomized trial with 2-year follow-up. Am J Gastroenterol 2001;96:1409-16.

36 Levenstein S. Peptic ulcer at the end of the 20th century: biological and psychological risk factors. Can J Gastroenterol 1999;13:753-9.

37 Friedman GD, Siegelaub MS, Seltzer CC. Cigarettes, alcohol, coffee and peptic ulcer. N Engl J Med 1974;290:469-73.

38 Everhart JE, Kruszon-Moran D, Perez-Peres Gl, et al. Seroprevalence and ethnic differences in Helicobacter pylori infection among adults in the Unites States. J Infect Dis 2000;181:1359-63.

39 Chou SP. An examination of the alcohol consumption and peptic ulcer association-Results of a national survey. Alcohol Clin Exp Res 1994; 18:149-53.

40 Rosenstock SJ, Jørgensen T, Andersen LP, et al. Association of Helicobacter pylori infection with lifestyle, chronic disease, body-indices, and age at menarche in Danish adults. Scand J Public Health 2000;28:32-40

41 Brenner H, Rothenbacher D, Bode $G$, et al. Inverse graded relation between alcohol consumption and active infection with Helicobacter pylori. Am J Epidemiol 1999;149:571-6.

42 de Lorimier AA. Alcohol, wine, and health. Am J Surg 2000; 180:357-61

43 Weisse ME, Eberly B, Person DA. Wine as a digestive acid: comparative antimicrobial effects of bismuth salicylate and red and white wine. BM 1995:311:1657-60

44 Tiønneland $\mathbf{A M}$, Grønbæk M, Stripp $C$, et al. Wine intake and diet in a random sample of 48,763 Danish men and women. Am J Clin Nutr $1999 \cdot 69: 49-54$ 